\title{
Ảnh hưởng của hàm lượng tro bay thay thế một phần xi măng đến các tính chất của bê tông cường độ cao
}

\author{
Đoàn Công Chánh ${ }^{1}$, Nguyễn Phú Nhuận ${ }^{1}$, Trần Văn Khánh ${ }^{1}$, Huỳnh Trọng Phước ${ }^{2^{*}}$ \\ ${ }^{1}$ Khoa Kỹ thuật và Công nghệ, Trường Đại học Trà Vinh. \\ ${ }^{2}$ Khoa Công nghệ, Trường Đại học Cần Thơ
}

TỪ KHOÁ

Bê tông cường độ cao

Tro bay

Độ sụt

Cường độ chịu nén

Độ co khô

\begin{abstract}
TÓM TẮT
Nghiên cứu này được thực hiện nhằm mục đích đánh giá khả năng sử dụng nguồn phụ phẩm tro bay từ nhà máy nhiệt điện trong chế tạo bê tông cường độ cao. Ảnh hưởng của hàm lượng tro bay dùng để thay thế một phần xi măng ( 0 - 50 \% với bước tăng $10 \%)$ đến các tính chất kỹ thuật của bê tông cường độ cao đã được nghiên cứu thông qua hệ thống các thí nghiệm bao gồm: đánh giá độ sụt, khối lượng thể tích, cường độ chịu nén, độ hút nước, độ co khô và vận tốc truyền sóng siêu âm. Kết quả thí nghiệm cho thấy tính công tác của hỗn hợp bê tông tăng và độ hút nước của mẫu bê tông cũng tăng tương ứng với hàm lượng tro bay trong cấp phối. Trong khi đó, cường độ chịu nén và vận tốc truyền sóng siêu âm giảm khi tăng hàm lượng tro bay thay thế xi măng. Việc thay thế xi măng bằng tro bay mang lại hiệu quả trong việc làm giảm khối lượng thể tích và độ co khô của bê tông. Các mẫu bê tông trong nghiên cứu này có chất lượng và độ bền tốt với giá trị tốc độ truyền sóng siêu âm ở mức $>4570 \mathrm{~m} / \mathrm{s}$. Kết quả nghiên cứu cũng cho thấy có thể thay thế đến $40 \%$ xi măng bằng tro bay trong sản xuất bê tông cường độ cao với giá trị cường độ chịu nén ở 28 ngày tuổi $\geqslant 55 \mathrm{MPa}$.
\end{abstract}

\begin{abstract}
This study evaluates the possibility of using fly ash, a by-product of coal thermal power plants, in the production of high-strength concrete. The influence of fly ash as a partial cement substitution (by $0-50 \%$ with an interval of $10 \%$ ) on the engineering properties of the high-strength concrete was investigated through a test series of workability, dry density, compressive strength, water absorption, drying shrinkage, and ultrasonic pulse velocity. The experimental results show that the workability of fresh concrete mixture and water absorption of concrete samples increased as increasing fly ash content in the mixtures. Meanwhile, compressive strength and ultrasonic pulse velocity were reduced with increasing fly ash replacement levels. The replacement of cement with fly ash was effective in reducing dry density and drying shrinkage of hardened concrete. The concrete samples produced in this study achieved good quality and durability with ultrasonic pulse velocity values of above $4570 \mathrm{~m} / \mathrm{s}$. The test results also reveal that fly ash could be used to replace up to $40 \%$ of cement in the production of high-strength concrete with compressive strength value at 28 days of $\geqslant 55 \mathrm{MPa}$.
\end{abstract}

\section{Giới thiệu}

Trong những năm qua, đã có rất nhiều kết quả nghiên cứu chỉ ra rằng tro bay, một loại phụ phẩm chủ yếu của các nhà máy nhiệt điện than, có tiềm năng tái sử dụng rất lớn do có hàm lượng khoáng cao. Tro bay là một dạng vật liệu pozzolan được sử dụng rất nhiều trong lĩnh vực vật liệu xây dựng. Việc ứng dụng tro bay có thể cải thiện được các tính chất kỹ thuật và độ bền của bê tông như độ thấm ion clorua, độ biến dạng [1] và vận tốc truyền sóng siêu âm [2]. Thêm vào đó, tro bay được kết hợp với một số thành phần vật liệu khác như sợi thép, muội silic, sợi polyplropylene có thể làm tăng cường độ chịu nén, cường độ chịu uốn và mô đun đàn hồi của bê tông [3-6]. Tại Việt Nam, loại tro bay có hàm lượng mất khi nung nhỏ hơn $11 \%$ có thể được sử dụng làm phụ gia khoáng để trộn vào xi măng trong khi các loại tro bay khác có thể được ứng dụng trong xây dựng đường, trong công nghiệp sản xuất bê tông, gạch không nung, v.v. Trong đó, ứng dụng tro bay để sản xuất bê tông nguyên khối chiếm tới $45 \%$ nhu cầu sử dụng tro bay trong ngành xây dựng [7]. Trong những năm gần đây, đã có một số nghiên cứu trong nước được thực hiện nhằm khảo sát khả năng ứng dụng các loại tro bay ở các địa phương khác nhau vào hoạt động xây dựng: Tiêu biểu như sử dụng tro bay nhiệt điện Phả Lại ở tỉnh Hải Dương để làm mặt đường ô tô [8], tro bay nhiệt điện Ninh Bình ở tỉnh Ninh Bình sử dụng để làm chất kết dính chịu nhiệt [9], tro bay nhiệt điện Duyên Hải ở tỉnh Trà Vinh được sử dụng để gia cố nền [10]. Nguyễn Văn Chính và Đặng Văn Mến [3] cho rằng, với hàm lượng khoáng cao, tro bay nhiệt điện Duyên Hải rất hữu ích trong việc cải thiện các tính chất của bê tông. Cụ thể, cường độ chịu nén và cấp chống thấm của bê tông chứa tro bay được tăng cường thông qua hiệu quả 
lấp lèn vào lỗ rỗng và phản ứng pozzolan của tro bay trong cấu trúc mẫu bê tông [3]. Tuy nhiên, các nghiên cứu trong nước liên quan đến sử dụng tro bay từ nhà máy nhiệt điện Duyên Hải để sản xuất bê tông cường độ cao còn hết sức hạn chế.

Mặt khác, một báo cáo từ Bộ Xây dựng [11] cho biết hiện cả nước có 25 nhà máy nhiệt điện đốt than đang hoạt động. Mỗi năm, có khoảng 13 triệu tấn tro-xỉ được phát phải ra môi trường, trong đó tro bay chiếm 80 - 85 \%. Lượng tro-xỉ phát thải được phân bố ở cả ba miền của Việt Nam, tập trung chủ yếu ở khu vực miền Bắc (chiếm 65 \%), trong khi miền Trung và miền Nam chỉ chiếm tương ứng khoảng $23 \%$ và $12 \%$ tổng lượng tro-xỉ thải. Trên thực tế, mặc dù nhiều địa phương đã có nhiều nỗ lực trong đẩy mạnh xử lý, sử dụng tro, xỉ, thạch cao làm nguyên liệu sản xuất vật liệu xây dựng và sử dụng trong các công trình xây dựng theo Quyết định số 452/QĐ-TTg nhưng kết quả vẫn chưa đạt được các mục tiêu như mong đợi. Tính đến cuối năm 2020, tổng lượng tro, xỉ nhiệt điện đã được tiêu thụ trên cả nước ở khoảng 44,5 triệu tấn, tương đương với khoảng $42 \%$ tổng trữ lượng tro, xỉ phát thải qua các năm [11]. Như vậy, có thể thấy trữ lượng tro bay còn tồn đọng lại rất lớn, cần có các nghiên cứu ứng dụng phù hợp nhằm làm giảm lượng tro bay tồn đọng này một cách có hiệu quả.

Dựa trên thực trạng trữ lượng tro bay còn tồn đọng và tiềm năng ứng dụng của nó trong công nghiệp bê tông, nghiên cứu này được đề xuất thực hiện với các mục tiêu: (1) Tái sử dụng nguồn phụ phẩm tro bay từ nhà máy nhiệt điện Duyên Hải tỉnh Trà Vinh trong sản xuất bê tông, mang lại hiệu quả nhất định về mặt môi trường tại địa phương; (2) Chế tạo loại bê tông tro bay có cường độ cao và có thể ứng dụng tốt trong các hoạt động xây dựng thực tế; (3) Đánh giá được ảnh hưởng của các hàm lượng khác nhau của tro bay dùng để thay thế một phần xi măng trong các cấp phối bê tông cường độ cao đến các tính chất của bê tông như độ sụt, khối lượng thể tích, cường độ chịu nén, độ hút nước, độ co khô và vận tốc truyền sóng siêu âm. Kết quả nghiên cứu như một giải pháp có hiệu quả trong xử lý lượng tro bay tồn đọng, tạo ra loại vật liệu xây dựng có chất lượng, thân thiện hơn với môi trường và phục vụ tốt cho nhu cầu xây dựng theo định hướng phát triển bền vững.

\section{Vật liệu và phương pháp thí nghiệm}

\subsection{Vật liệu và cấp phối}

Các vật liệu được sử dụng để chế tạo bê tông cường độ cao trong nghiên cứu này được thể hiện ở Hình 1 , cụ thể gồm: xi măng Nghi Sơn PC40, tro bay từ nhà máy nhiệt điện Duyên Hải 1 thuộc tỉnh Trà Vinh, cát sông, cát nghiền, đá mi, phụ gia siêu dẻo loại $\mathrm{G}$ và nước. Khối lượng riêng, thành phần hóa học của xi măng và tro bay được thể hiện ở Bảng 1. Có thể thấy được khối lượng riêng của tro bay nhỏ hơn so với khối lượng riêng của xi măng, do đó khi sử dụng tro bay để thay thế một phần xi măng có thể sẽ làm giảm khối lượng riêng của bê tông. Lưu ý rằng tro bay được sử dụng trong nghiên cứu là tro bay loại $\mathrm{F}$ theo TCVN 10302:2014 [12] với tổng hàm lượng $\mathrm{SiO}_{2}, \mathrm{Al}_{2} \mathrm{O}_{3}$, và $\mathrm{Fe}_{2} \mathrm{O}_{3}$ lớn hơn $70 \%$. Các tính chất của cát sông, cát nghiền và đá mi được cung cấp ở Bảng 2. Trong nghiên cứu này, do cát sông có thành phần hạt tương đối mịn trong khi cát nghiền có thành phần hạt khá thô, do đó cốt liệu nhỏ sẽ được pha trộn từ $65 \%$ cát sông và $35 \%$ cát nghiền (tỉ lệ được chọn theo thực nghiệm) với mục đích đạt được đường cong cấp phối hạt thỏa mãn theo TCVN 7570:2006 [13].

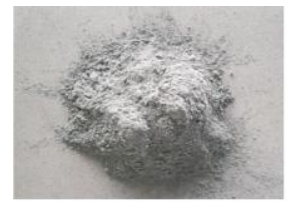

(a) Xi măng

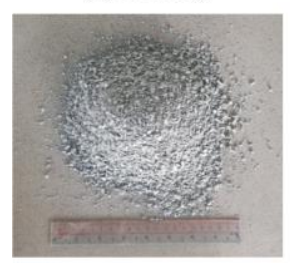

(d) Cát nghiền

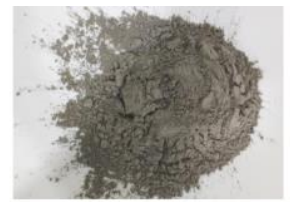

(b) Tro bay

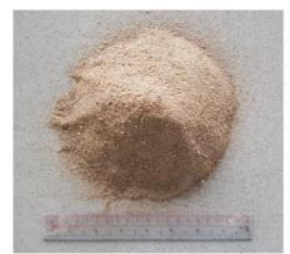

(e) Cát sông

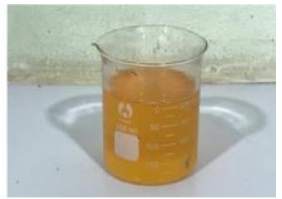

(c) Phụ gia siêu dẻo

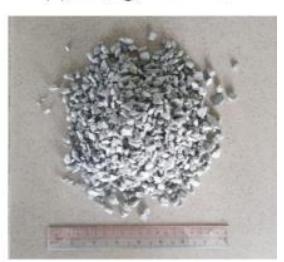

(f) Đá mi
Hình 1. Các loại vật liệu dùng trong nghiên cứu.

\section{Bảng 1.}

Các tính chất vật lý và hóa học của xi măng và tro bay.

\begin{tabular}{ccccccccc}
\hline \multirow{2}{*}{ Loại vật liệu } & $\begin{array}{c}\text { Khối lượng riêng } \\
\left(\mathrm{g} / \mathrm{cm}^{3}\right)\end{array}$ & $\mathrm{SiO}_{2}$ & $\mathrm{Al}_{2} \mathrm{O}_{3}$ & $\mathrm{Fe}_{2} \mathrm{O}_{3}$ & $\mathrm{MgO}$ & $\mathrm{CaO}$ & $\mathrm{SO}_{3}$ & $\mathrm{Khác}$ \\
\cline { 3 - 9 } & 3,06 & 23,5 & 6,0 & 3,7 & 2,0 & 59,9 & 0,4 & 1,1 \\
Xi măng & 2,22 & 59,2 & 26,7 & 6,1 & 0,9 & 1,1 & 0,1 & 3,9 \\
Tro bay & & &
\end{tabular}

\section{Bảng 2.}

Các tính chất của cát sông, cát nghiền và đá mi.

\begin{tabular}{ccccc}
\hline Loại vật liệu & Khối lượng riêng $\left(\mathrm{g} / \mathrm{cm}^{3}\right)$ & Độ hút nước (\%) & Mô đun độ lớn & $\begin{array}{c}\text { Đường kính hạt lớn nhất } \\
(\mathrm{mm})\end{array}$ \\
\hline Cát sông & 2,69 & 1,12 & 1,58 & - \\
Cát nghiền & 2,67 & 1,50 & 3,10 & - \\
Đá mi & 2,74 & 0,60 & - & 9,5 \\
\hline
\end{tabular}


Bảng 3.

Thành phần vật liệu dùng để chế tạo bê tông (đơn vị: kg/m³).

\begin{tabular}{cccccccc}
\hline Cấp phối & Xi măng & Tro bay & Cát sông & Cát nghiền & Đá mi & Nước & Phụ gia \\
\hline CP1 & 756 & 0 & 297 & 160 & 1068 & 189 & 3,8 \\
CP2 & 675 & 75 & 295 & 159 & 157 & 1059 & 187 \\
CP3 & 594 & 149 & 292 & 156 & 1049 & 186 \\
CP4 & 516 & 221 & 290 & 155 & 1031 & 184 \\
CP5 & 438 & 292 & 287 & 153 & 1022 & 183 \\
CP6 & 362 & 362 & 285 & & & 181 & \\
\hline
\end{tabular}

Bảng 4. Tổng hợp các phương pháp thí nghiệm.

\begin{tabular}{lccc}
\hline \multicolumn{1}{c}{ Tên các thí nghiệm được thực hiện } & Kích thước mẫu (mm) & Tuổi mẫu (ngày) & Tiêu chuẩn áp dụng \\
\hline Độ sụt & - & Sau khi trộn & TCVN 3106:1993 [15] \\
Cường độ chịu nén & $\emptyset 150 \times 300$ & 1,28 & TCVN 3118:1993 [16] \\
Khối lượng thể tích khô & $150 \times 150 \times 150$ & 28 & TCVN 3115:1993 [17] \\
Độ hút nước & $150 \times 150 \times 150$ & 28 & TCVN 3113:1993 [18] \\
Độ co khô & $75 \times 75 \times 285$ & $0,7,14,28$ & TCVN 3117:1993 [19] \\
Vận tốc truyền sóng siêu âm & $\emptyset 100 \times 200$ & 28 & TCVN 9357:2012 [20] \\
\hline
\end{tabular}

Các cấp phối bê tông cường độ cao sử dụng tro bay trong nghiên cứu này được thiết kế theo chỉ dẫn của TCVN 10306:2014 [14]. Cấp phối CP1 là cấp phối đối chứng không sử dụng tro bay. Để khảo sát ảnh hưởng của việc thay thế một phần xi măng bằng tro bay đến các tính chất kỹ thuật của bê tông, trên cơ sở cấp phối CP1, xi măng được thay thế dần bằng tro bay theo các tỷ lệ $10 \%, 20 \%, 30 \%, 40 \%$ và $50 \%$ theo khối lượng được các cấp phối kí hiệu lần lượt là $\mathrm{CP} 2, \mathrm{CP} 3, \mathrm{CP} 4$, $\mathrm{CP5}$ và $\mathrm{CP6}$. Tỷ lệ nước/ chất kết dính (gồm xi măng và tro bay) được cố định ở mức 0,25 cho tất cả các cấp phối. Độ sụt của các hỗn hợp bê tông được điều chỉnh ở khoảng $8-10 \mathrm{~cm}$ bằng cách sử dụng các hàm lượng phụ gia siêu dẻo khác nhau. Thành phần vật liệu cho mỗi $\mathrm{m}^{3}$ bê tông được tính toán và trình bày ở Bảng 3.

\subsection{Phương pháp thí nghiệm}

\subsubsection{Chuẩn bị mẫu thí nghiệm}

Phương pháp phối trộn và quá trình chuẩn bị mẫu được tóm tắt như sau: (1) Chuẩn bị vật liệu và cân định lượng theo đúng thành phần cấp phối như trình bày ở Bảng 3 , lượng nước và phụ gia siêu dẻo được hòa đều với nhau thành dung dịch nước-phụ gia trước khi sử dụng; (2) Xi măng và tro bay được trộn khô trong máy trộn khoảng 1 phút, dần dần cho một lượng dung dịch nước-phụ gia đã chuẩn bị vào và tiếp tục trộn trong khoảng 2 phút để được hỗn hợp chất kết dính đồng đều; (3) Cho tất cả lượng cát sông và cát nghiền vào máy trộn đồng thời thêm một ít nước-phụ gia và tiếp tục trộn trong khoảng 2 phút; (4) Cuối cùng, cho toàn bộ lượng đá mi và lượng nước-phụ gia còn lại vào máy trộn, tiếp tục trộn trong khoảng 2 phút để được hỗn hợp bê tông đồng nhất. Sau khi trộn xong, hỗn hợp bê tông được kiểm tra độ sụt. Các cấp phối bê tông đạt được độ sụt yêu cầu sẽ tiếp tục được tạo mẫu để sử dụng cho các thí nghiệm khác nhau (xem chi tiết ở Bảng 4).

\subsubsection{Phương pháp thí nghiệm}

Hệ thống các thí nghiệm để đánh giá ảnh hưởng của việc sử dụng tro bay thay thế một phần xi măng trong cấp phối bê tông cường độ cao được thực hiện bao gồm: Xác định độ sụt của hỗn hợp bê tông, xác định cường độ chịu nén, khối lượng thể tích, độ hút nước, độ co khô và vận tốc truyền sóng siêu âm qua các mẫu bê tông đã đóng rắn. Chi tiết thí nghiệm gồm kích thước mẫu, ngày tuổi thí nghiệm và tiêu chuẩn áp dụng cho mỗi thí nghiệm được tổng hợp ở Bảng 4. Hình ảnh thiết bị sử dụng cho các thí nghiệm cũng được mô tả ở Hình 2.

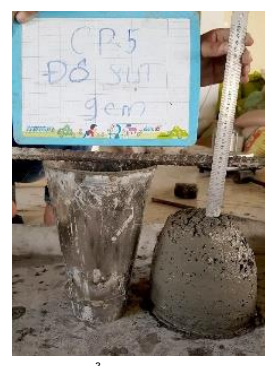

(a) Kiểm tra độ sụt

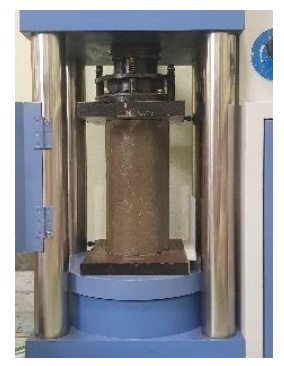

(b) Kiểm tra cường độ chịu nén

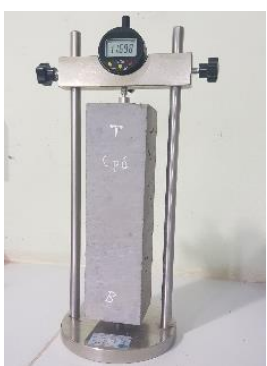

(c) Kiểm tra độ co khô

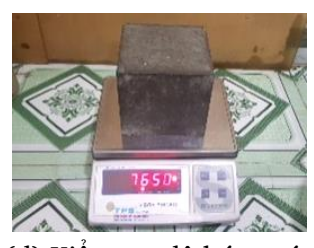

(d) Kiểm tra độ hút nước

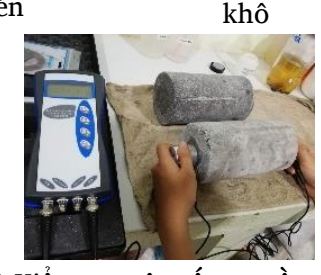

(e) Kiểm tra vận tốc truyền sóng siêu âm
Hình 2. Hình ảnh kiểm tra một số tính chất của hỗn hợp bê tông và bê tông. 


\section{Kết quả nghiên cứu}

\section{1. Độ sụt}

Kết quả thí nghiệm xác định độ sụt của các hỗn hợp bê tông được trình bày ở Hình 3 . Như đã trình bày ở trên, độ sụt của tất cả các hỗn hợp bê tông được kiểm soát trong khoảng $8-10 \mathrm{~cm}$ bằng cách điều chỉnh hàm lượng phụ gia siêu dẻo được sử dụng. Thực tế ghi nhận được rằng hỗn hợp bê tông có tính công tác tốt hơn khi sử dụng tro bay thay thế một phần xi măng trong thành phần cấp phối. Điều này được chứng minh qua hàm lượng phụ gia siêu dẻo được dùng trong cấp phối. Quan sát Hình 3 thấy rằng, ở cùng khoảng độ sụt mong muốn, cấp phối bê tông chứa càng nhiều tro bay thì nhu cầu sử dụng phụ gia siêu dẻo cũng càng giảm tương ứng. Nguyên nhân của việc này có thể là do sự sai khác về hình dạng hạt cầu của tro bay và hình dạng hạt góc cạnh của xi măng [3]. Nói cách khác, dạng hạt hình cầu của tro bay làm giảm nội ma sát giữa các hạt và từ đó tăng độ linh động của hỗn hợp bê tông. Ngoài ra, độ linh động của hỗn hợp bê tông còn bị ảnh hưởng bởi khối lượng riêng của vật liệu. Cụ thể, do tro bay có khối lượng riêng nhẹ hơn so với xi măng nên khi thay thế xi măng bằng tro bay với cùng một khối lượng, tổng thể tích chất kết dính được tăng lên chi phối khả năng làm việc của hỗn hợp bê tông [21].

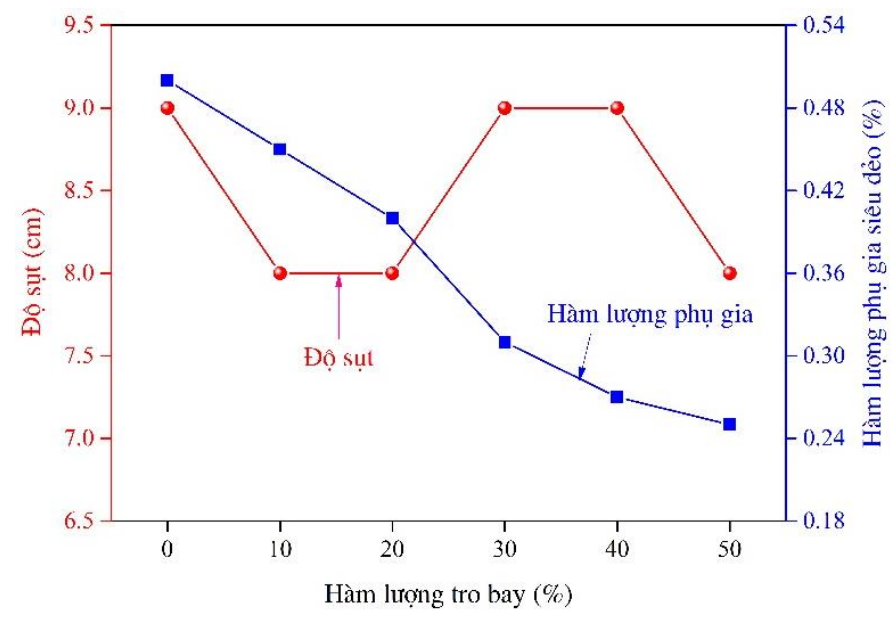

Hình 3. Độ sụt của các hỗn hợp bê tông.

\subsection{Cường độ chịu nén}

Ảnh hưởng của việc thay thế một phần xi măng bằng tro bay đến cường độ chịu nén của các mẫu bê tông được trình bày ở Hình 4. Có thể quan sát thấy một xu hướng chung là giá trị cường độ chịu nén của các mẫu bê tông giảm khi tăng hàm lượng tro bay trong cấp phối bê tông. Cụ thể, ở thời điểm sau một ngày chế tạo thì mẫu bê tông đối chứng có cường độ chịu nén cao nhất ở 37,92 $\mathrm{MPa}$. Giá trị này giảm dần xuống còn 32,95 $\mathrm{MPa}, 26,79 \mathrm{MPa}, 22,64 \mathrm{MPa}, 18,98 \mathrm{MPa}$ và 10,82 $\mathrm{MPa}$ tương ứng với các hàm lượng tro bay lần lượt là $10 \%, 20 \%, 30 \%, 40 \%$ và $50 \%$. Xu hướng tương tự cũng được ghi nhận cho các mẫu bê tông ở tuổi 28 ngày. Tuy nhiên, đáng lưu ý là các mẫu bê tông chứa 20 \% tro bay có giá trị cường độ chịu nén cao hơn một chút so với mẫu bê tông chứa $10 \%$ tro bay. Ở các hàm lượng tro bay cao hơn 20 \% thì xu hướng giảm cường độ chịu nén của bê tông vẫn được ghi nhận tương tự như ở 1 ngày tuổi. Hiện tượng này cũng đã được ghi nhận trong các nghiên cứu trước $[22,23]$. Sự tăng cường độ theo thời gian là kết quả của quá trình thủy hóa của xi măng và phản ứng pozzolan của tro bay [21, 22]. Tuy nhiên, tốc độ phát triển cường độ của các mẫu chứa tro bay nhìn chung là chậm hơn so với mẫu đối chứng nhất là ở tuổi ngắn ngày, chủ yếu là đo đặc điểm chậm phản ứng pozzolan của tro bay [24]. Bên cạnh đó, khi thay thế xi măng bằng tro bay làm giảm sự hình thành portlandite, cản trở phản ứng pozzolan và từ đó làm chậm quá trình phát triển cường độ của bê tông $[21,25]$. Ngoài ra, có thể chỉ có một phần tro bay đóng vai trò là chất kết dính tham gia các phản ứng hóa học, phần còn lại không phản ứng đóng vai trò như cốt liệu mịn trong hệ thống. Mặc dù phản ứng pozzolan tạo ra keo C-S-H và các hạt không phản ứng đóng vai trò cốt liệu lèn các lỗ rỗng trong mẫu nhưng vẫn không thể bù đắp được hậu quả của hiệu ứng pha loãng, dẫn đến cường độ chịu nén của bê tông bị giảm so với mẫu đối chứng [4, 6].

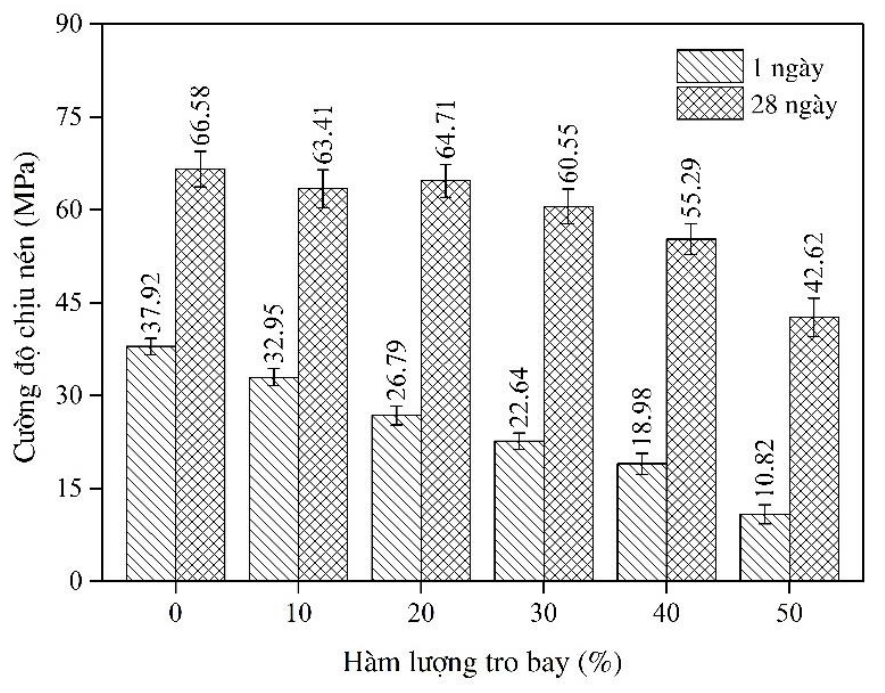

Hình 4. Cường độ chịu nén của bê tông.

\section{3. Độ hút nước}

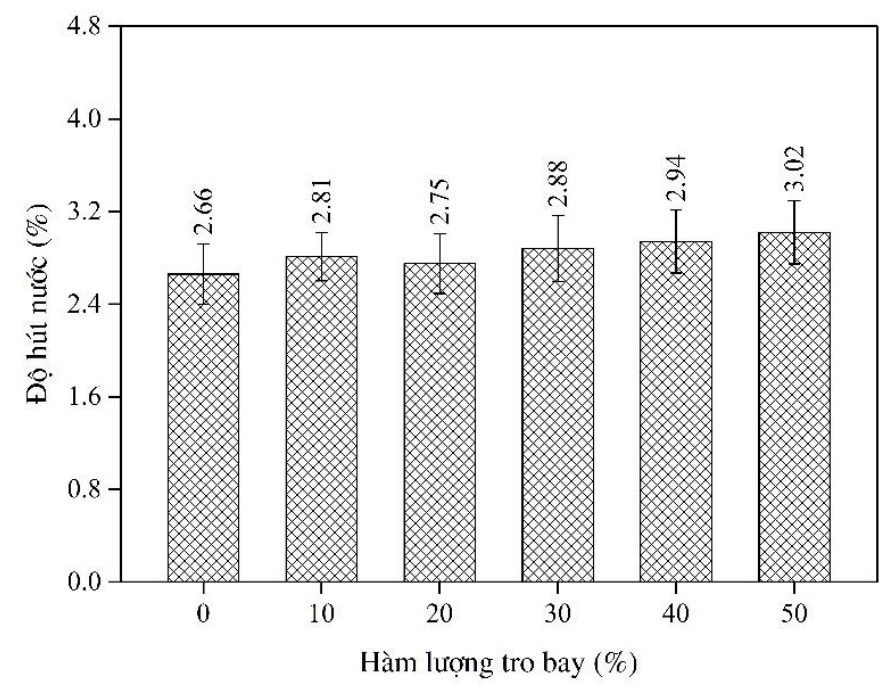

Hình 5. Độ hút nước của bê tông ở 28 ngày tuổi. 
Hình 5 trình bày kết quả thí nghiệm xác định độ hút nước của các mẫu bê tông ở 28 ngày tuổi. Độ hút nước của tất cả các mẫu bê tông trong nghiên cứu này ở mức tương đối thấp, dao động trong khoảng 2,66 \% - 3,02 \%. Có thể thấy các giá trị độ hút nước tăng nhẹ khi tăng hàm lượng tro bay thay thế xi măng trong các cấp phối bê tông. Cụ thể, độ hút nước của mẫu đối chứng là $2,66 \%$, các mẫu bê tông chứa $10 \%, 20 \%, 30 \%, 40 \%$ và $50 \%$ tro bay có giá trị độ hút nước lần lượt là $2,81 \%, 2,75 \%, 2,88 \%, 2,94 \%$ và $3,02 \%$. Joseph và Ramamurthy [26] đã nhận định rằng hàm lượng tro bay tăng làm tăng độ hút nước do phản ứng pozzolan xảy ra chậm trong mẫu chứa tro bay. Nhìn chung, độ hút nước của bê tông không thay đổi đáng kể khi thay thế xi măng bằng tro bay ở các hàm lượng $10 \%$ - 50 \%. Wongkeo và cộng sự [4] cũng đã ghi nhận kết quả tương tự trong nghiên cứu của họ.

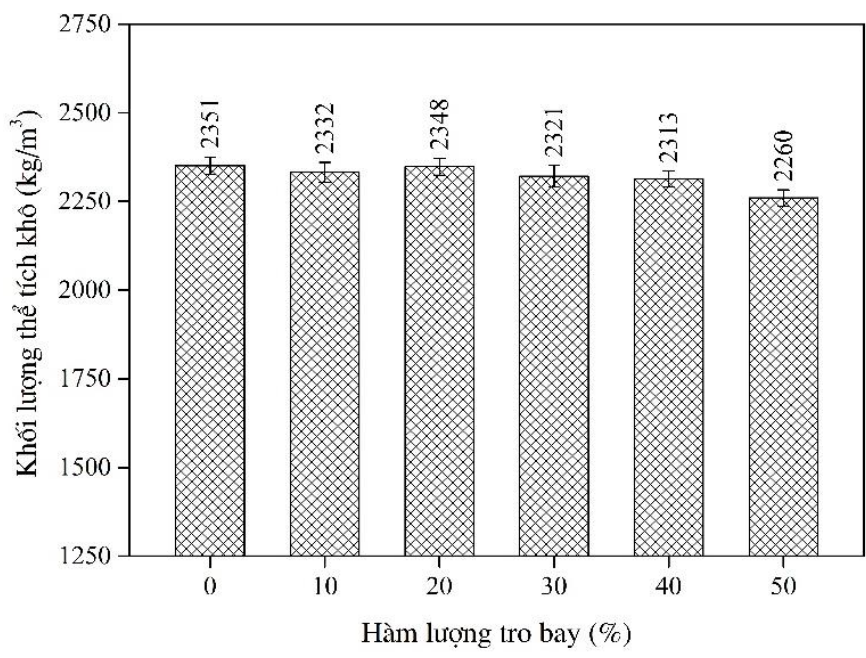

Hình 6. Khối lượng thể tích khô của bê tông ở 28 ngày tuổi.

\subsection{Khối lượng thể tích khô}

Kết quả xác định khối lượng thể tích khô của các mẫu bê tông ở 28 ngày tuổi được trình bày ở Hình 6 . Có thể thấy rằng giá trị khối lượng thể tích khô của các mẫu bê tông giảm nhẹ tương ứng với việc gia tăng hàm lượng tro bay thay thế xi măng trong cấp phối. Ở mẫu đối chứng, giá trị khối lượng thể tích khô được ghi nhận là $2351 \mathrm{~kg} / \mathrm{m}^{3}$, giá trị này giảm nhẹ xuống còn $2332 \mathrm{~kg} / \mathrm{m}^{3}, 2348 \mathrm{~kg} / \mathrm{m}^{3}, 2321 \mathrm{~kg} / \mathrm{m}^{3}$, $2313 \mathrm{~kg} / \mathrm{m}^{3}$ và $2260 \mathrm{~kg} / \mathrm{m}^{3}$ tương ứng với các cấp phối bê tông chứa $10 \%, 20 \%, 30 \%, 40 \%$ và $50 \%$ tro bay. Có thể thấy rằng các mẫu bê tông chứa nhiều tro bay hơn sẽ có trọng lượng bản thân nhẹ hơn. Đây được xem là một ưu điểm của việc ứng dụng tro bay trong bê tông. Kết quả này chủ yếu là do tro bay có khối lượng riêng nhỏ hơn so với khối lượng riêng của xi măng như đã trình bày ở Bảng 1.

\section{5. Độ co khô}

Độ co khô của các mẫu bê tông được đánh giá thông qua giá trị độ thay đổi chiều dài các mẫu bê tông quan sát đến 28 ngày tuổi (xem Hình 7). Ở 28 ngày tuổi, giá trị độ co khô của các mẫu bê tông chứa $0 \%$, $10 \%, 20 \%, 30 \%, 40 \%$ và $50 \%$ tro bay được ghi nhận lần lượt là $0,049 \%,-0,048 \%,-0,047 \%,-0,045 \%,-0.041 \%$ và $-0,038 \%$. Nhìn chung, việc sử dụng tro bay để thay thế một phần xi măng mang lại hiệu quả tích cực trong việc cải thiện độ co khô của các mẫu bê tông. Theo đó, hàm lượng tro bay trong cấp phối càng tăng thì mức độ co khô của các mẫu bê tông càng giảm. Atis [23] đã giải thích sự thay đổi tích cực này là do lượng nhiệt thủy hóa thấp hơn trong các mẫu bê tông có hàm lượng tro bay cao và các thành phần không thủy hóa có thể hoạt động như cốt liệu hạn chế sự co khô xảy ra. Bên cạnh đó, Lee và các cộng sự [27] cho rằng việc giảm co khô của bê tông có thể quy cho hiệu ứng pha loãng khi thay thế xi măng bằng tro bay. Nói cách khác, tro bay làm cho phản ứng thủy hóa xảy ra chậm hơn, mà phản ứng pozzolan chỉ có thể xảy ra khi $\mathrm{Ca}(\mathrm{OH})_{2}$ được hình thành từ phản ứng thủy hóa của xi măng. Mặc khác, khi tỷ lệ nước/chất kết dính là cố định, việc thêm tro bay vào làm giảm hàm lượng vôi trong hỗn hợp dẫn đến tốc độ thủy hóa giảm xuống, kết quả là độ co khô trong các mẫu bê tông thấp hơn [25]. Như vậy, sử dụng tro bay để thay thế xi măng còn được xem là một giải pháp tích cực và có hiệu quả trong việc hạn chế độ co khô của các mẫu bê tông.

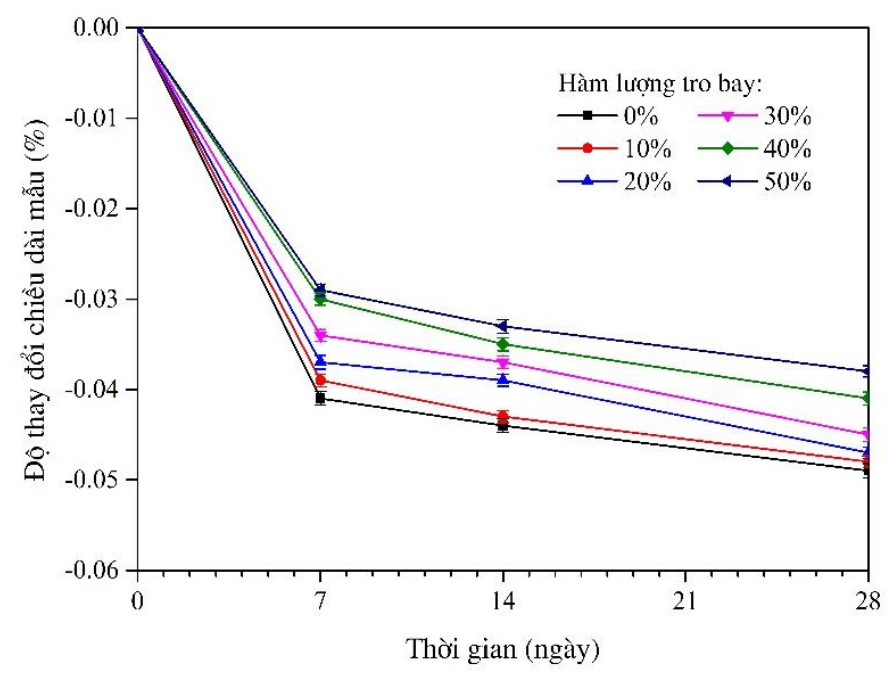

Hình 7. Độ co khô của bê tông.

\subsection{Vận tốc truyền sóng siêu âm}

Giá trị vận tốc truyền sóng siêu âm được dùng như một chỉ tiêu phản ánh độ bền của mẫu bê tông. Giá trị này còn được dùng để phản ánh độ đặc chắc và dự đoán độ rỗng hay vết nứt bên trong mẫu bê tông [28]. Kết quả thí nghiệm xác định vận tốc truyền sóng siêu âm qua các mẫu bê tông ở 28 ngày tuổi được trình bày ở Hình 8 . Vận tốc tuyền sóng siêu âm qua các mẫu bê tông ghi nhận được từ $4606 \mathrm{~m} / \mathrm{s}$ đến 4762 $\mathrm{m} / \mathrm{s}$. Trong đó, giá trị lớn nhất thuộc ghi nhận tại mẫu đối chứng (4762 $\mathrm{m} / \mathrm{s}$ ) và các giá trị này có xu hướng giảm dần khi tăng hàm lượng tro bay thay thế xi măng. Nguyên nhân của hiện tượng này là do ở độ tuổi 28 ngày, tốc độ và mức độ diễn ra phản ứng hydrate hóa chậm với sự hiện diện của tro bay, sản phẩm sau phản ứng ít được tạo thành làm cho mẫu kém đặc chắc hơn so với mẫu đối chứng [27, 29]. Bên cạnh đó, có thể do hoạt tính pozzolan của tro bay thấp nên không góp phần đáng kể vào sự tăng cường độ của bê tông, dẫn đến việc giảm tốc độ truyền sóng siêu âm [2]. Tuy giá trị vận tốc truyền sóng siêu âm giảm khi tăng hàm lượng tro bay, các giá trị vận tốc truyền sóng siêu âm của 
tất cả các mẫu bê tông đều cao hơn so với mức 4570 m/s. Do đó, các mẫu bê tông trong nghiên cứu này được xếp ở vào loại bê tông chất lượng rất tốt [30].

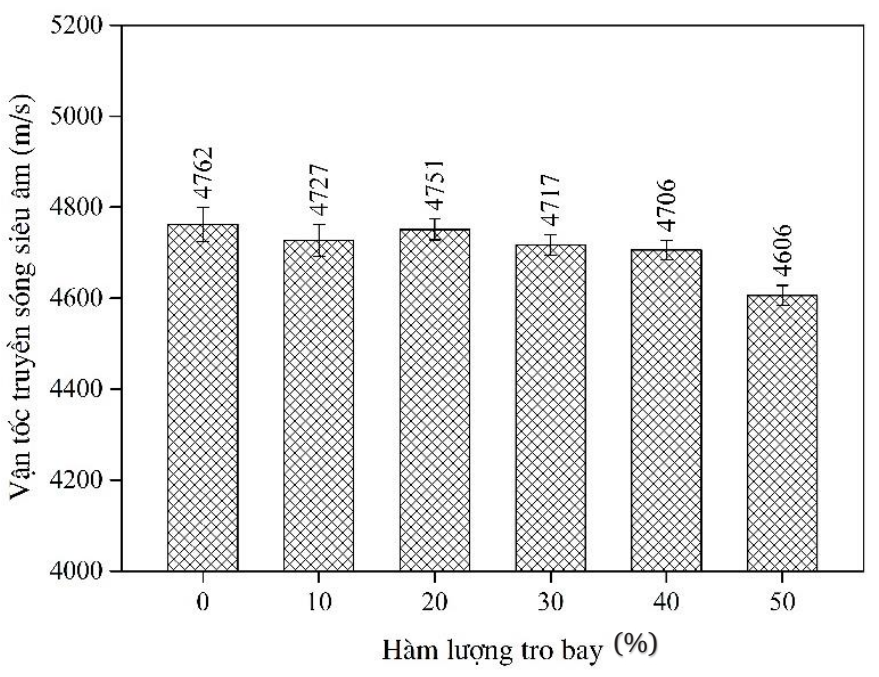

Hình 8. Vận tốc truyền sóng siêu âm của bê tông ở 28 ngày tuổi.

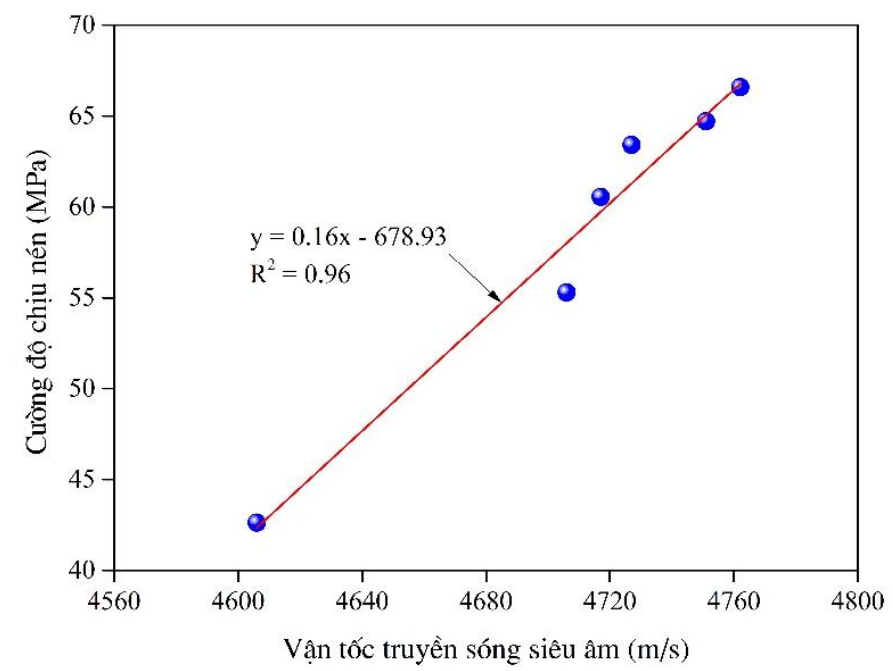

Hình 9. Mối quan hệ giữa vận tốc truyền sóng siêu âm và cường độ chịu nén của bê tông ở 28 ngày tuổi.

Mối quan hệ giữa cường độ chịu nén và vận tốc truyền sóng siêu âm của bê tông được thể hiện ở Hình 9. Qua đó, có thể thấy được giữa cường độ chịu nén và vận tốc truyền sóng siêu âm của bê tông có mối liên hệ tuyến tính. Thông qua hàm tương quan đường thẳng $\mathrm{y}=0,16 \mathrm{x}$ - 678,93 với độ tin cậy $\mathrm{R}^{2}=96$ \%, có thể suy đoán được giá trị cường độ chịu nén hoặc vận tốc truyền sóng siêu âm tại bất kì độ tuổi nào của bê tông khi biết trước một trong hai đại lượng.

\section{Kết luận}

Nghiên cứu này đã đánh giá ảnh hưởng của việc thay thế một phần xi măng bằng tro bay từ nhà máy nhiệt điện Duyên Hải thuộc tỉnh Trà Vinh đến các tính chất kỹ thuật của bê tông cường độ cao. Dựa trên kết quả thí nghiệm thu được, có thể rút ra một số kết luận chủ yếu như sau:

Tính công tác hay độ sụt của hỗn hợp bên tông được cải thiện khi sử dụng tro bay để thay thế một phần xi măng trong các cấp phối bê tông. Theo đó, nhu cầu sử dụng phụ gia siêu dẻo trong các cấp phối bê tông có tro bay cũng thấp hơn so với cấp phối chỉ sử dụng xi măng làm chất kết dính.

Hàm lượng tro bay trong các cấp phối bê tông có ảnh hưởng đến các tính chất kỹ thuật của nó: Khi tăng hàm lượng tro bay thay thế xi măng thì giá trị cường độ chịu nén, khối lượng thể tích khô, độ co khô và vận tốc truyền sóng siêu âm giảm nhẹ, trong khi độ hút nước thì tăng nhưng không đáng kể. Tuy vậy, tất cả các mẫu bê tông trong nghiên cứu này được đánh giá là có chất lượng và độ bền rất tốt với giá trị vận tốc truyền sóng siêu âm ở mức $>4570$ m/s.

Việc sử dụng tro bay thay thế xi măng trong bê tông cường độ cao mang lại hiệu quả thiết thực trong việc cắt giảm trọng lượng bản thân của kết cấu bê tông, đồng thời làm giảm đáng kể hiện tượng co khô của bê tông và từ đó góp phần cải thiện chất lượng và độ bền của công trình sử dụng loại bê tông này.

So với tiêu chí của bê tông cường độ cao (cường độ chịu nén ở 28 ngày tuổi $\geqslant 55 \mathrm{MPa}$ [14]), thì có thể thay thế đến $40 \%$ lượng xi măng trong cấp phối bê tông bằng tro bay. Khi đó, giá trị cường độ chịu nén của bê tông ở 28 ngày tuổi đạt được ứng với mức thay thế này là 55,29 MPa. Dựa trên kết quả nghiên cứu đạt được, mức thay thế 30 $40 \%$ xi măng bằng tro bay được đề xuất cho chế tạo bê tông cường độ cao.

\section{Lời cảm ơn}

Kết quả nghiên cứu được tài trợ bởi Trường Đại học Trà Vinh thông qua hợp đồng số 223/HĐ.HĐKH\&ĐT-ĐHTV, ngày 11 tháng 8 năm 2020.

\section{Tài liệu tham khảo}

[1]. Nath P., Sarker P. (2011), Effect of fly ash on the durability properties of high strength concrete, Procedia Engineering 14, pp. 1149-1156.

[2]. Rao S. K., Sravana P., Rao T. C. (2016), Experimental studies in ultrasonic pulse velocity of roller compacted concrete pavement containing fly ash and M-sand, International Journal of Pavement Research and Technology 9(4), pp. 289-301.

[3]. Nguyễn Văn Chính, Đặng Văn Mến (2019), Ảnh hưởng của tro bay nhiệt điện Duyên Hải đến cường độ chịu nén và khả năng chống thấm của bê tông, Tạp chí Khoa học và Công nghệ Đại học Đà Nẵng, số 17, tr. 11-14.

[4]. Wongkeo W., Thongsanitgarn P., Ngamjarurojana A., Chaipanich A. (2014), Compressive strength and chloride resistance of self-compacting concrete containing high level fly ash and silica fume, Materials and Design 64, pp. 261-269.

[5]. Karahan O., Atis C. D. (2011), The durability properties of polypropylene fiber reinforced fly ash concrete, Materials and Design 32(2), pp. 10441049.

[6]. Leung H. Y., Kim J., Nadeem A., Jaganathan J., Anwar M. P. (2016), Sorptivity of self-compacting concrete containing fly ash and silica fume, Construction and Building Materials 113, pp. 369-375. 
[7]. Hoàng Thị Phương, Vũ Quốc Vương (2020), Tiềm năng vật liệu xây dựng từ tro xỉ - Giải pháp tái chế bảo bệ môi trường và hiệu quả kinh tế, Tạp chí Khoa học Kỹ thuật Thủy lợi và Môi trường, số 70, tr. 118-123.

[8]. Thái Minh Quân, Nguyễn Thanh Sang, Lê Thu Trang, Hoàng Tiến Văn (2021), Một nghiên cứu thực nghiệm bê tông hàm lượng tro bay cao có cường độ cao làm mặt đường ô tô ở Việt Nam, Tạp chí Khoa học Công nghệ, số 3, tr. 105-109.

[9]. Đỗ Thị Phượng, Lê Văn Trí, Vũ Minh Đức, Nguyễn Nhân Hòa (2018), Chất kết dính chịu nhiệt sử dụng tro bay, Tạp chí Khoa học và Công nghệ Đại học Đà Nẵng, số 5 , tr. 51-55.

[10]. Phạm Thanh Tùng, Châu Trường Linh, Nguyễn Thành Đạt (2018), Nghiên cứu sử dụng tro bay từ nhà máy nhiệt điện Duyên Hải làm cọc đất-tro bay gia cố nền đất yếu hạ tầng dự án khu đô thị mới phía Đông đường Mậu Thân, thành phố Trà Vinh, Tạp chí Khoa học Công nghệ Giao thông Vận tải, số $27+28$, tr. 142-148.

[11]. Bộ Xây dựng, Xử lý tro xỉ thải nhiệt điện: Thực trạng và những nút thắt cần gỡ, ngày đăng 16/11/2020, ngày truy cập 17/7/2021.

[12]. TCVN 10302:2014 (2014), Phụ gia hoạt tính tro bay dùng cho bê tông, vữa xây và xi măng, Hà Nội, Việt Nam.

[13]. TCVN 7570:2006 (2006), Cốt liệu cho bê tông và vữa - Yêu cầu kỹ thuật, Hà Nội, Việt Nam.

[14]. TCVN 10306:2014 (2014), Bê tông cường độ cao - Thiết kế thành phần mẫu hình trụ, Hà Nội, Việt Nam.

[15]. TCVN 3106:1993 (1993), Hỗn hợp bê tông nặng - Phương pháp thử độ sụt, Hà Nội, Việt Nam.

[16]. TCVN 3118:1993 (1993), Bê tông nặng - Phương pháp xác định cường độ nén, Hà Nội, Việt Nam.

[17]. TCVN 3115:1993 (1993), Bê tông nặng - Phương pháp xác định khối lượng thể tích, Hà Nội, Việt Nam.

[18]. TCVN 3113:1993 (1993), Bê tông nặng - Phương pháp xác định độ hút nước, Hà Nội, Việt Nam.

[19]. TCVN 3117:1993 (1993), Bê tông nặng - Phương pháp xác định độ co, Hà Nội, Việt Nam.

[20]. TCVN 9357:2012 (2012), Bê tông nặng - Phương pháp thử không phá hủy - Đánh giá chất lượng bê tông bằng vận tốc xung siêu âm, Hà Nội, Việt Nam.

[21]. de Matos P. R., Foiato M., Jr L. R. P. (2019), Ecological, fresh state and long-term mechanical properties of high-volume fly ash high-performance self-compacting concrete, Construction and Building Materials 203, pp. 282-293.

[22]. Siddique R. (2004), Performance characteristics of high-volume class F fly ash concrete, Cement and Concrete Research 34(3), pp. 487-493.

[23]. Atis C. D. (2003), High-volume fly ash concrete with high strength and low drying shrinkage, Journal of Materials in Civil Engineering 15(2), pp. 153156.

[24]. Topcu I. B., Canbaz M. (2007), Effect of different fibers on the mechanical properties of concrete containing fly ash, Construction and Building Materials 21(7), pp. 1486-1491.

[25]. Saha A. K. (2018), Effect of class F fly ash on the durability properties of concrete, Sustainable Environment Research 28(1), pp. 25-31.

[26]. Joseph G., Ramamurthy K. (2009), Influence of fly ash on strength and sorption characteristics of cold-bonded fly ash aggregate concrete, Construction and Building Materials 23(5), pp. 1862-1870.

[27]. Lee H. K., Lee K. M., Kim B. G. (2003), Autogenous shrinkage of highperformance concrete containing fly ash, Magazine of Concrete Research 55(6), pp. 507-515.

[28]. Estévez E., Martín D. A., Argiz C., Sanjuán M. Á. (2020), Ultrasonic pulse velocity - Compressive strength relationship for Portland cement mortars cured at different conditions, Crystals 10(2), pp. 133.
[29]. Kumar M., Sinha A. K., Kujur J. (2020), Mechanical and durability studies on high-volume fly-ash concrete, Structural Concrete 22(S1), pp. E1036E1049.

[30]. Malhotra V. M. (1976), Testing hardened concrete: Nondestructive methods. American Concrete Institute, Detroit, US. 